\title{
Trigeminal Neuralgia Secondary to Meningiomas and Vestibular Schwannoma Is Improved after Stereotactic Radiosurgery: A Systematic Review and Meta-Analysis
}

\author{
Iulia Peciu-Florianu ${ }^{a}$ Jean Régis ${ }^{b}$ Marc Levivier ${ }^{c, d}$ Michaela Dedeciusova ${ }^{e, f}$ \\ Nicolas Reyns ${ }^{a} \quad$ Constantin Tuleasca ${ }^{a}, c, d, g$ \\ ${ }^{a}$ Centre Hospitalier Regional Universitaire de Lille, Roger Salengro Hospital, Lille, France; ${ }^{b}$ Stereotactic and \\ Functional Neurosurgery Service and Gamma Knife Unit, CHU Timone, Marseille, France; ${ }^{C}$ Neurosurgery Service \\ and Gamma Knife Center, Department of Clinical Neurosciences, Lausanne University Hospital (CHUV), Lausanne, \\ Switzerland; ${ }^{d}$ Faculty of Biology and Medicine (FBM), University of Lausanne (Unil), Lausanne, Switzerland; \\ eFirst Faculty of Medicine, Charles University in Prague, Prague, Czech Republic; ${ }^{\mathrm{f}}$ Department of Neurosurgery \\ and Neuro-Oncology, Military University Hospital Prague, Prague, Czech Republic; ${ }^{9}$ Signal Processing Laboratory \\ (LTS-5), Ecole Polytechnique Fédérale de Lausanne (EPFL), Lausanne, Switzerland
}

\section{Keywords}

Stereotactic radiosurgery - Gamma knife surgery •

Trigeminal neuralgia - Vestibular schwannoma ·

Meningioma

\begin{abstract}
Introduction: Trigeminal neuralgia (TN) secondary to tumors is encountered in up to $6 \%$ of patients with facial pain syndromes and is considered to be associated with tumors affecting the trigeminal nerve pathways. The most frequent are meningiomas and vestibular schwannomas (VS). Stereotactic radiosurgery (SRS) has emerged as a valuable treatment, with heterogeneity of clinical results. We sought to review the medical literature on TN treated with SRS for meningiomas and VS and investigate the rates of improvement of TN symptoms. Methods: We reviewed articles published between January 1990 and December 2019 in PubMed. Pain relief after SRS, the maintenance of pain relief, and TN recurrence and complications were evaluated with separate
\end{abstract}

karger@karger.com www.karger.com/sfn

Karger $\stackrel{\text { ' }}{5}$

GOPEN ACCESS
(C) 2020 The Author(s)

Published by S. Karger AG, Basel

This is an Open Access article licensed under the Creative Commons Attribution-NonCommercial-4.0 International License (CC BY-NC) (http://www.karger.com/Services/OpenAccessLicense), applicable to the online version of the article only. Usage and distribution for commercial purposes requires written permission. meta-analyses, taking into account the data on individual patients. Results: Pain relief after SRS was reported as Barrow Neurological Institute (BNI) pain intensity scores of BNI I in $50.5 \%$ (range $36-65.1 \%$ ) of patients and BNI I-IIll in $83.8 \%$ (range $77.8-89.8 \%$ ). There was no significant difference in series discussing outcomes for tumor targeting versus tumor and nerve targeting. Recurrences were described in $34.7 \%$ (range 21.7-47.6; tumor targeting). Maintenance of BNI I was reported in 36.4\% (range 20.1-52.7) and BNI I-IIIb in 41.2\% (range 29.8-52.7; tumor targeting series). When both the nerve and the tumor were targeted, only 1 series reported $86.7 \%$ with BNI I-IIIb at last follow-up. Complications were encountered in $12.6 \%$ (range 6.3-18.8; tumor targeting series) of patients; however, they were much higher, as high as $26.7 \%$, in the only study reporting them after targeting both the nerve and the tumor. The most common complication was facial numbness. Conclusion: SRS for TNB secondary to

I.P.-F. and J.R. contributed equally as first authors and N.R. and C.T. as senior authors.
Constantin Tuleasca

Department of Clinical Neurosciences, Lausanne University Hospital (CHUV) Neurosurgery Service and Gamma Knife Center

$\mathrm{CH}-1011$ Lausanne (Switzerland)

constantin.tuleasca@chuv.ch or constantin.tuleasca@gmail.com 
benign tumors, such as meningiomas and VS, is associated with favorable clinical course, but less favorable than in idiopathic TN. There was, however, heterogeneity among reports and targeting approaches. Although targeting both the nerve and the tumor seemed to achieve better longterm results, the rate of complications was much higher and the number of patients treated was limited. Future clinical studies should focus on the standard reporting of clinical outcomes and randomization of targeting methods.

(C) 2020 The Author(s)

Published by S. Karger AG, Basel

\section{Introduction}

Idiopathic trigeminal neuralgia (TN) is frequently generated by nerve dysfunction due to the vascular compression of the trigeminal nerve root as it enters the brainstem. Microvascular decompression remains the standard treatment modality, whenever feasible $[1,2]$. Other alternatives are radiofrequency lesioning, glycerol rhizotomy, balloon percutaneous compression [3], and radiation techniques. It has been acknowledged that stereotactic radiosurgery (SRS) alleviates idiopathic TN with very few side effects $[4,5]$.

$\mathrm{TN}$ secondary to tumors is encountered in up to $6 \%$ of patients with facial pain syndromes and is considered to be associated with tumors affecting the trigeminal nerve [6-9]. These tumors are confined to the TN pathways and might include cavernous sinus, Meckel's cave, cerebellopontine angle, petrous apex, petroclival, and can be benign or malignant, e.g., meningiomas, trigeminal schwannomas, vestibular schwannomas (VS), epidermoid cysts, metastasis, and so on $[6-8,10]$. Meningiomas and schwannomas are the most common tumors to cause secondary TN. Medication alone has a short-term effect, with a high failure rate, ranging from 63 to 100\% [8]. Microsurgical resection is the most effective means of relieving pain, but some tumors cannot be completely excised and resection is associated with morbidity and mortality [6-8]. Also, in patients with an excessive surgical risk, including the elderly, or those with significant comorbidities, open microsurgical resection might not be the treatment of choice. Moreover, if the tumors fill in the trigeminal cistern, transovale needle placement is not feasible. In this context, and during the past 2 decades, SRS has been considered a valuable alternative to microsurgical resection.

Here, we focus on the outcomes of SRS for secondary TN generated by benign tumors, particularly the most common ones, meningiomas and VS [6,7]. Only a few studies have been dedicated to the treatment of tumor- related facial pain with radiosurgery. In the literature, different targeting strategies and a heterogeneity of clinical results are reported. Hence, there is a need to better understand outcomes and further improve the selection of patients for this indication.

\section{Materials and Methods}

Article Selection and Data Extraction

A PubMed search was performed for entries between January 1990 and December 2019 using the following query guidelines: ([trigeminal AND (radiosurgery OR Gamma Knife)] AND [vestibular schwannoma]; or combinations with [meningioma], [skull-base], [benign skull-base]). The beginning of the 1990s was chosen as the starting date because prior to this, there were only a few studies published on meningiomas and VS in general that included SRS. Inclusion criteria required that each article be a peerreviewed clinical study or a case series of meningiomas and VS treated with SRS, independent of the device (Linear AcceleratorLinac; Gamma Knife, GK) used. As such, case reports, non-English studies, conference papers, and abstracts were not included. Some studies advocated targeting the tumor (most $[9,11-20]$ ), while others advocated targeting the tumor and the nerve (the minority $[21,22])$. If a study reported a vast majority of meningiomas and VS and only 1-2 cases of other pathologies, it was included in our analysis. Exclusion criteria were: cases treated with fractionated radiotherapy (unless this was the minority in a larger series) [12], series reporting 2 procedures (only reported by Huang et al. [14]), or series focusing on trigeminal schwannomas which are reputed to have different results and only 1 target (the tumor) [23]. Were also excluded series reporting malignant lesions, as these have a different radiobiology and $\alpha$-to- $\beta$ ratio [24]. The article selection is illustrated in Figure 1, which includes studies detailed in Tables 1 and 2. Two separate reviewers applied the inclusion criteria to the PubMed search result; there were no disagreements. Moreover, 4 separate reviewers applied the exclusion criteria to the articles that remained, and we finally included 13 series [9, 11-22].

This study was performed in accordance with the published Preferred Reporting Items for Systematic Reviews and Meta-Analyses (PRISMA) guidelines [25]. In extracting data from these studies, we paid attention to the classical outcomes usually described after SRS for idiopathic TN as per individual patient (in studies individually reporting the outcomes), i.e., pain relief after SRS, pain recurrence, the maintenance of pain relief, and complications [4,5]. Freedom from pain was evaluated whenever possible using Barrow Neurological Institute (BNI) pain intensity scores of I = no trigeminal pain and no medication; II = occasional pain, but not requiring medication; III = some pain, but adequately controlled with medication; IV = some pain, but not adequately controlled with medication; and $\mathrm{V}=$ continuous severe pain or no pain relief [26].

With regard to the radiology aspect, the probability of an incorrect diagnosis based only upon neuroimaging findings in the absence of histology was previously evaluated by Flickinger et al. [27] as $1.4 \%$. All studies analyzed here stated that all cases had typical imaging features of meningiomas and VS. One series, by Kano et al. [15], applied a unique protocol where all patients received an intravenous dose of $20-40 \mathrm{mg}$ of methylprednisolone after radiosurgery. 


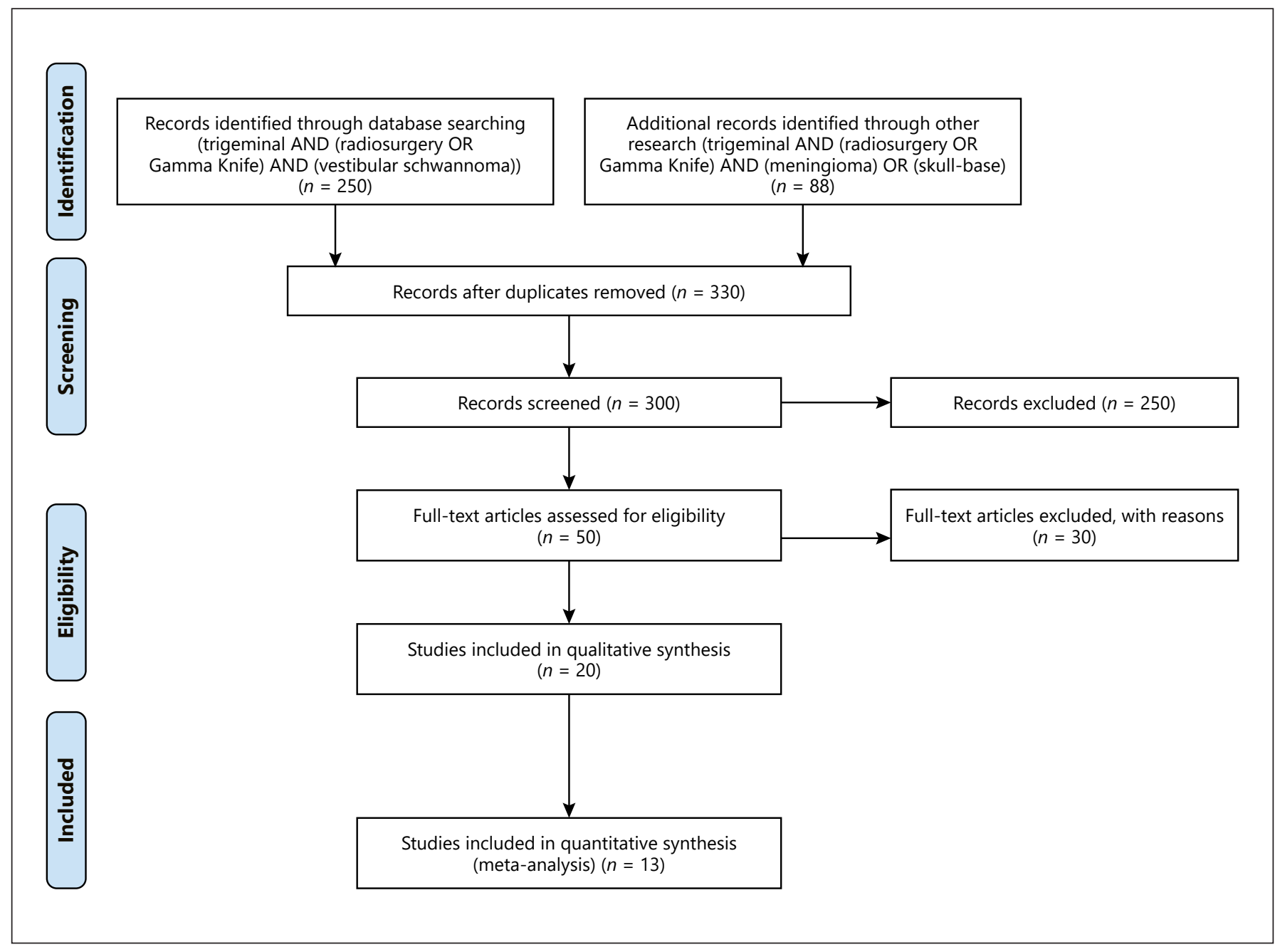

Fig. 1. Flow chart describing study selection according to the PRISMA statement.

Statistical Analysis Using OpenMeta (Analyst) and a

Random-Effects Model

Due to the high variation in study characteristics, a statistical analysis using a binary random-effects model (DerSimonian-Laird method) was performed. We used OpenMeta (Analyst) from the Agency for Healthcare Research and Quality.

Weighted summary rates were determined using meta-analytical models. Testing for heterogeneity was performed for each meta-analysis. Pooled estimates using meta-analytical techniques were obtained for all the individual outcomes previously described in the same section.

\section{Results}

\section{Pain Relief after SRS}

Pain relief after SRS was associated with a higher maximum dose and single-branch involvement [19].
Tumor Targeting Series

Pain relief after SRS BNI I was reported in 52/103 cases, i.e., a rate of $50.5 \%$ (range $36-65.1 ; I^{2}=58.4 \%$, $p_{\text {heterogeneity }}=0.035, p<0.001$; Fig. 2a). Pain relief after SRS BNI I-IIIb was encountered in $189 / 228$ cases, i.e., a rate of $83.8 \%$ (range $77.8-89.8 ; I^{2}=32.69 \%$, $p_{\text {heterogeneity }}=$ $0.147, p<0.001$; Fig. 2b).

Tumor and Nerve Targeting Series (in the Same Session or Separate Sessions)

Pain relief after SRS BNI I-IIIb was encountered in $29 / 36$ cases, i.e., a rate of $83.7 \%$ (range $62.3-90.8 \%$; $I^{2}=$ $71.1 \%$, $p_{\text {heterogeneity }}=0.063, p<0.001$; Fig. $2 \mathrm{c}$ ). Time to pain relief is reported in Table 2. Time to decrease in tumor volume was considered longer than time to TN response (18.6 vs. 5.3 months) [11]. 
Table 1. Tumor incidence, follow-up, duration of symptoms prior to SRS, dose, target, target volumes and tumor decrease/control

\begin{tabular}{|c|c|c|c|c|c|c|c|}
\hline $\begin{array}{l}\text { First author } \\
\text { [ref.], year }\end{array}$ & $\begin{array}{l}\text { Tumor incidence } \\
\text { and type }\end{array}$ & $\begin{array}{l}\text { Duration of } \\
\text { follow-up, } \\
\text { months }\end{array}$ & $\begin{array}{l}\text { Duration of } \\
\text { symptoms, } \\
\text { months (range) }\end{array}$ & $\begin{array}{l}\text { Dose, Gy } \\
\text { (range) }\end{array}$ & Target & $\begin{array}{l}\text { Target volume, } \\
\mathrm{mL} \text { (range) }\end{array}$ & $\begin{array}{l}\text { Tumor } \\
\text { decrease, } \\
\text { control }\end{array}$ \\
\hline $\begin{array}{l}\text { Chang [11], } \\
1999(n=27)\end{array}$ & $\begin{array}{l}14(51.9 \%) \mathrm{M} \\
11(40.7 \%) \mathrm{VS} \\
1(3.7 \%) \text { cancer of } \\
\text { the nasopharynx } \\
1(3.7 \%) \text { chordoma }\end{array}$ & 32.1 & $23(0.7-89)$ & $26.4(16-35)$ & the tumor & $7.5(1.3-23.3)$ & $14 / 25(56 \%),-$ \\
\hline $\begin{array}{l}\text { Pollock [9], } \\
2000(n=9)\end{array}$ & M & $45(12-90)$ & - & $18(16-20)$ & the tumor & $9.7(1.9-27.2)$ &,$- 15 / 16(93.8 \%)$ \\
\hline $\begin{array}{l}\text { Régis [17], } \\
2001(n=53)\end{array}$ & $\begin{array}{l}\text { Group IV: } \\
24(45.3 \%) \mathrm{M}, \\
17(32.1 \%) \mathrm{VS}, \\
2(3.8 \%) \text { metastasis, } \\
2(3.8 \%) \text { CSM, } \\
2(3.8 \%) \mathrm{HPC}, \\
1(1.9 \%) \text { PA }\end{array}$ & $55.2(2-84)$ & - & $\begin{array}{l}\text { II } 80-90 \\
\text { III } 15.3(12-20) \\
\text { IV } 14.2(8-25)\end{array}$ & $\begin{array}{l}\text { II: the nerve (cistern) }(n=3) \\
\text { III: the part of the tumor that } \\
\text { supposedly included the nerve } \\
(n=4) \text { if the nerve root could } \\
\text { not be identified } \\
\text { IV: the tumor }(n=46)\end{array}$ & - & - \\
\hline $\begin{array}{l}\text { Kreil [16], } \\
2005(n=23)\end{array}$ & - & - & - & - & - & - & - \\
\hline $\begin{array}{l}\text { Huang [14], } \\
2008(n=21)\end{array}$ & $\begin{array}{l}12(57.1 \%) \mathrm{M} \\
9(42.9 \%) \mathrm{VS}\end{array}$ & $57.8(36-94)$ & & $\begin{array}{l}\text { men: } 12.7(12-15) \\
\text { VS: } 13(11.5-16)\end{array}$ & the tumor & $\begin{array}{l}\text { men: } 8.2(1.1-21) \\
\text { VS: } 5.6(2-9.2)\end{array}$ & 17 (80\%), $100 \%$ \\
\hline $\begin{array}{l}\text { Kano [15], } \\
2011(n=12)\end{array}$ & 12 (100\%) PCM & $68(25-180)$ & $31(1.3-120.3)$ & $13(11-16)$ & the tumor & $3.8(1-15.9)$ & \\
\hline $\begin{array}{l}\text { Squire [18], } \\
2012(n=21)\end{array}$ & $\begin{array}{l}15(71.4 \%) \mathrm{M} \\
4(19.1 \%) \mathrm{VS} \\
2(9.5 \%) \mathrm{TS}\end{array}$ & 45.6 & - & $12(11-13)$ & the tumor & - & - \\
\hline $\begin{array}{l}\text { Tanaka [19], } \\
2013(n=31)\end{array}$ & $\begin{array}{l}17(54.8 \%) \text { PFM } \\
9(29 \%) \text { CSM } \\
5(16.1 \%) \text { TS }\end{array}$ & $50(12-184)$ & $\begin{array}{l}18.3 \pm 23.4 \\
(0.5-84)\end{array}$ & $15(13-20)$ & $\begin{array}{l}1(3 \%) \text { the tumor and nerve } \\
\text { the tumor }(n=30)\end{array}$ & $\begin{array}{l}7.7(1.5-34.8) \\
(\mathrm{PIV})\end{array}$ & $\begin{array}{l}19(61 \%) \\
\text { decrease, } \\
11(35 \%) \text { stable }\end{array}$ \\
\hline $\begin{array}{l}\text { Kim }[21] \\
2016(n=15)\end{array}$ & $\begin{array}{l}11(73 \%) \mathrm{M} \\
3(20 \%) \text { VS } \\
1(7 \%) \text { TS }\end{array}$ & $38(12-78)$ & - & $\begin{array}{l}13(12.5-15) \mathrm{M} \\
12(11-13) \mathrm{VS} \\
15 \text { TS } \\
80(70-85) \mathrm{REZ}\end{array}$ & $\begin{array}{l}\text { A single session, both the } \\
\text { tumor and the nerve (REZ) }\end{array}$ & $1.7(0.1-4.9)$ & - \\
\hline $\begin{array}{l}\text { Park [22], } \\
2016(n=21)\end{array}$ & $21(100 \%) \mathrm{M}$ & $\begin{array}{l}44.4 \pm 32.4 \\
(12-108)\end{array}$ & - & $\begin{array}{l}12.5 \pm 1.1 \\
90\end{array}$ & $\begin{array}{l}\text { Two sessions: } \\
1-\text { the tumor } \\
2-\text { (after } 62 \pm 52 \text { months) } \\
\text { the trigeminal nerve }\end{array}$ & $3.3 \pm 2.83$ & $\begin{array}{l}12 / 15(80 \%) \\
15 / 15(100 \%)\end{array}$ \\
\hline
\end{tabular}

AVM, arteriovenous malformations; CSM, cavernous sinus meningioma; EC, epidermoid cyst; HPC, hemangiopericytoma; M, meningioma; PA, pleomorphic adenoma; PCM, petroclival meningioma; PFM, posterior fossa meningioma; VS, vestibular schwannoma; TS, trigeminal schwannoma; REZ, root entry zone; FRT, fractionated radiotherapy. 


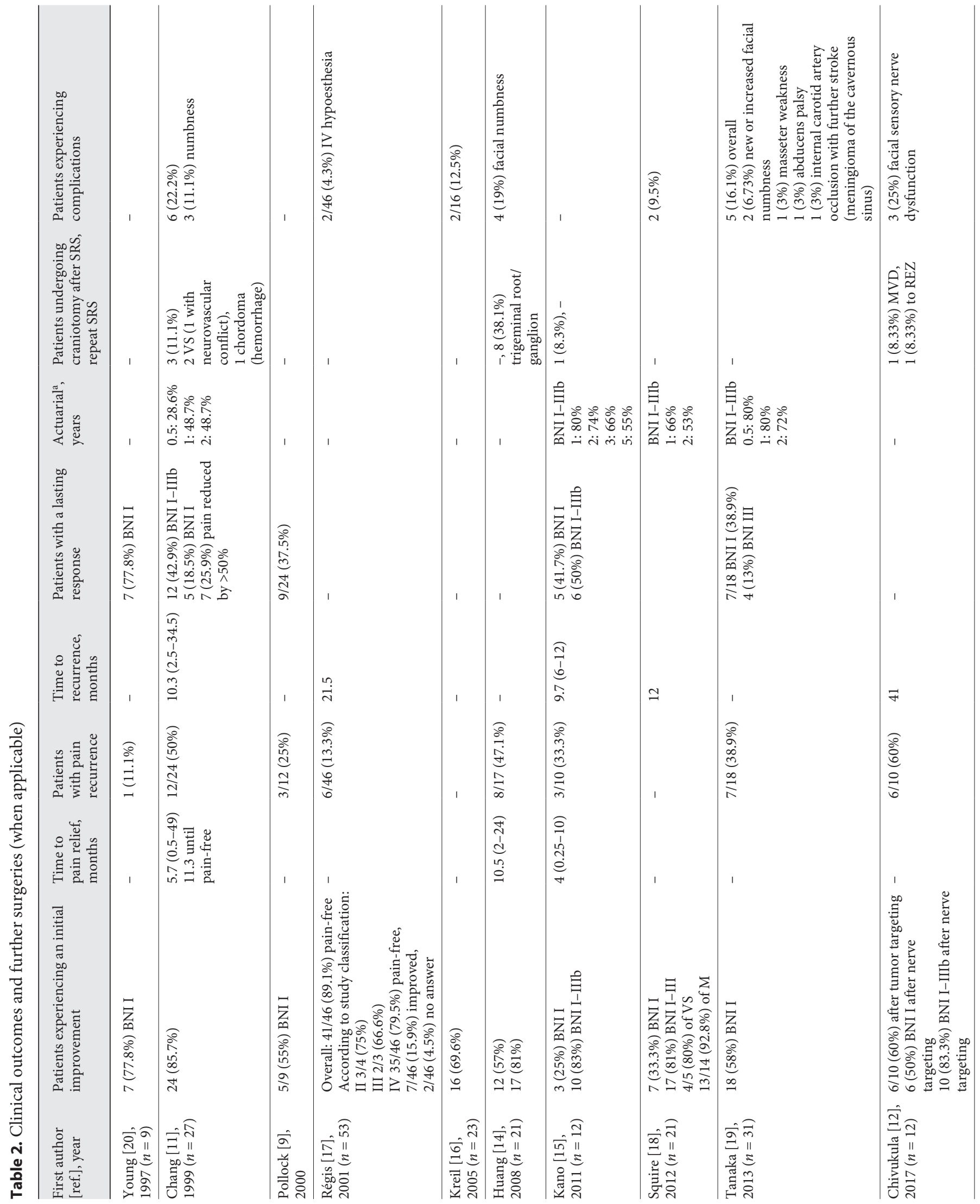




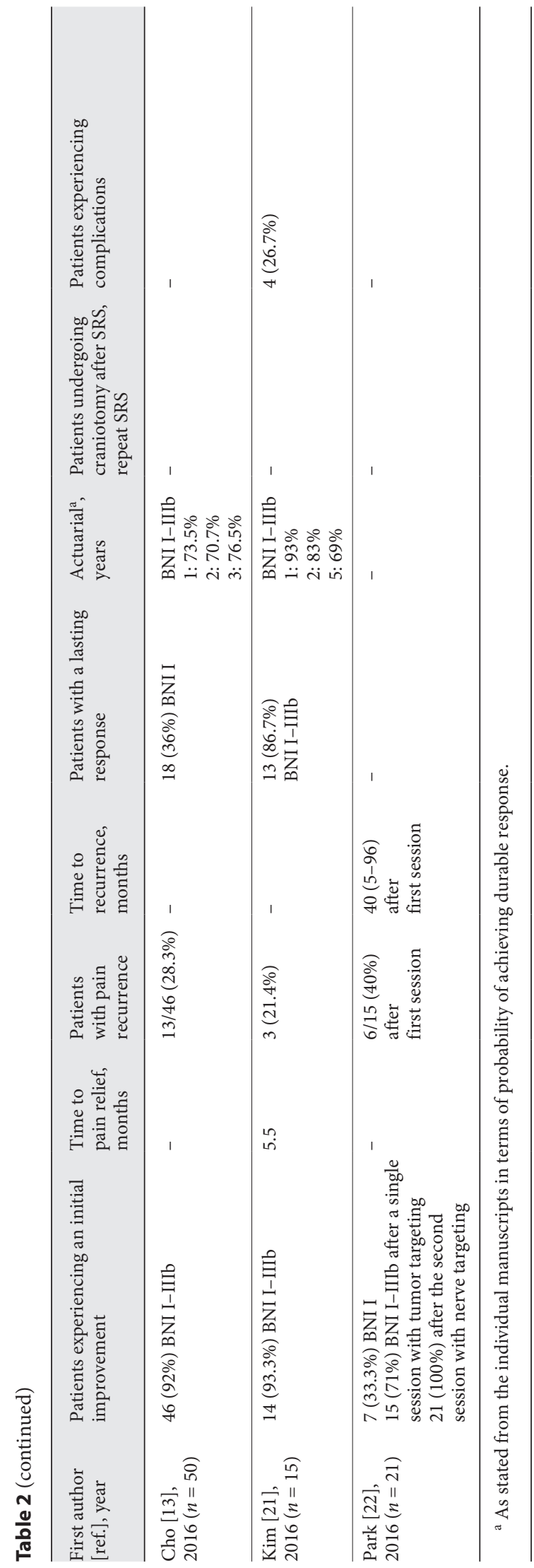

SRS for Trigeminal Neuralgia Secondary to Tumors
Maintenance of Pain Relief on a Long-Term Basis

Tumor shrinkage after SRS was not necessarily associated with a better clinical outcome, BNI I-IIIb [19].

Tumor Targeting Series

Maintenance of BNI I was reported in $42 / 129$ cases, for a rate of $36.4 \%$ (range $20.1-52.7 ;^{\wedge 2}=75.8 \%$, $p_{\text {heterogeneity }}=$ $0.002, p<0.001$; Fig. 3a). Moreover, pain relief after SRS BNI I-IIIb was encountered in 29/70 cases, for a rate of $41.2 \%$ (range $29.8-52.7 ; I^{2}=0 \%$, $p_{\text {heterogeneity }}=0.628, p<$ 0.001; Fig. 3b).

Tumor and Nerve Targeting Series (in the Same Session or Separate Sessions)

Kim et al. [21] reported 13/15 (86.7\%) BNI I-IIIb in their series.

\section{Recurrence}

Recurrence is described in 70/205 patients for series focusing on tumor targeting, for a rate of $34.7 \%$ (range $21.7-47.6 ; I^{2}=76.86 \%$, $p_{\text {heterogeneity }}<0.001, p<0.001$; Fig. $4 \mathrm{a})$.

\section{Complications}

Complications were reported in $24 / 174$ cases in series focusing on tumor targeting, for a rate of $12.6 \%$ (range $6.3-18.8 ; I^{2}=35.95 \%$, $p_{\text {heterogeneity }}=0.154, p<0.001$; Fig $4 b)$. Kim et al. [21] reported 4/15 (26.7\%) cases targeting both the tumor and the nerve.

\section{Discussion}

In the current literature, there is a gap of knowledge with regard to potential improvements in secondary TN related to meningiomas or VS. Here, we analyzed series independently of their targeting policy (i.e., the tumor itself vs. the tumor and the nerve vs. the nerve only). Pain relief after SRS was reported as BNI I in 50.5\% (range 36-65.1\%) and BNI I-IIIb in 83.8\% (range 77.8$89.8 \%$ ). There was no significant difference across series regarding the outcomes with tumor targeting and tumor and nerve targeting. Recurrence was described in $34.7 \%$ (range 21.7-47.6; tumor targeting). Maintenance of BNI I was reported in $36.4 \%$ (range 20.1-52.7) and maintenance of BNI I-IIIb in 41.2\% (range 29.8-52.7\%; tumor targeting series). When both the nerve and tumor were targeted, 1 series reported BNI I-IIIb in $86.7 \%$ at the last follow-up. Complications were encountered in $12.6 \%$ (range 6.3-18.8\%; tumor targeting series); however, the 
a Initial pain-free (tumor targeting) BN II

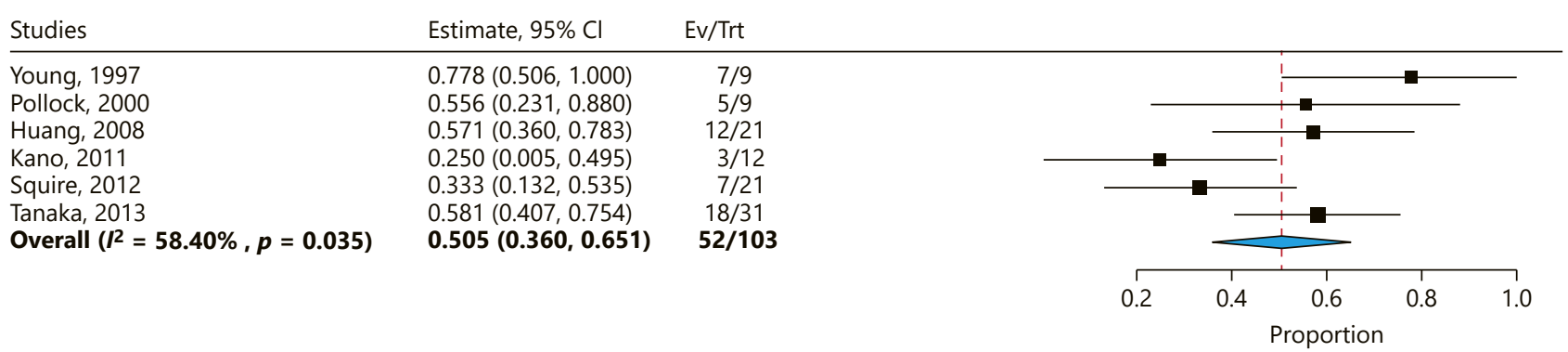

\section{b Initial pain-free (tumor targeting) BNI I-IIIb}

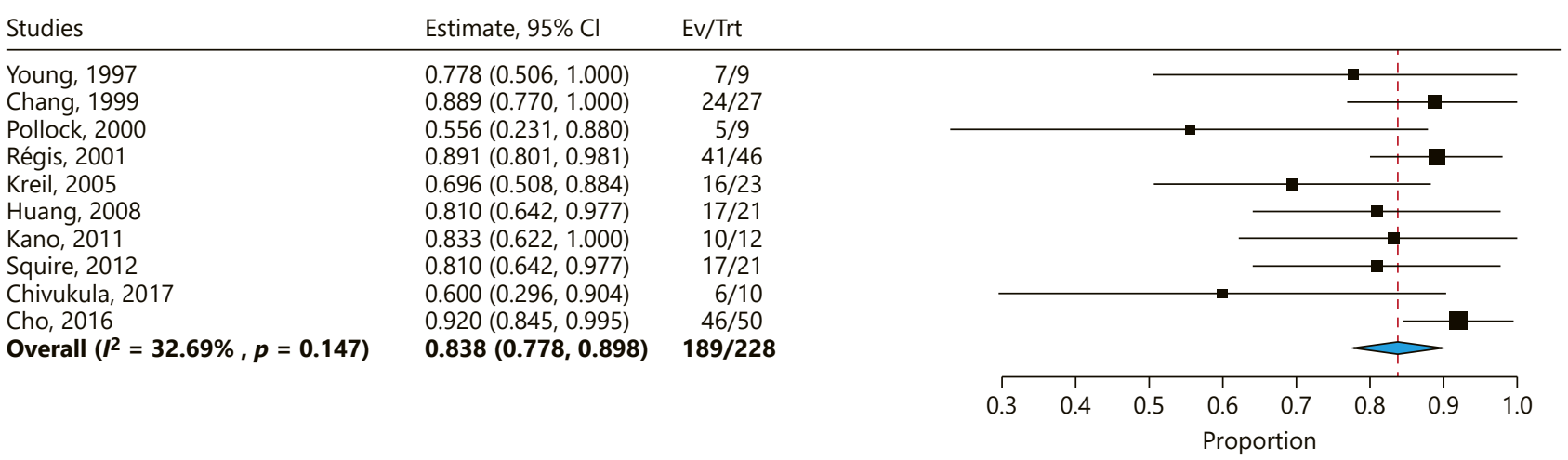

\section{Initial pain-free (tumor and nerve targeting) BNI I-IIlb}

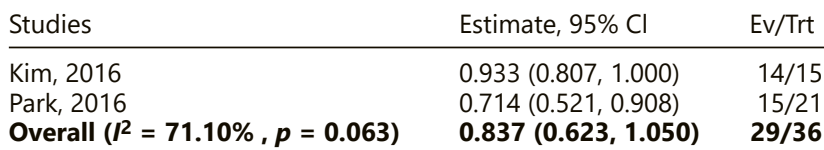

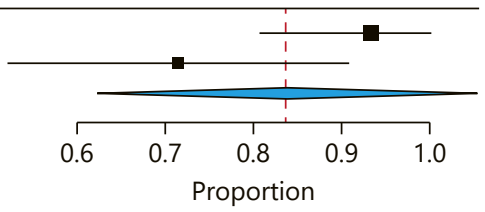

Fig. 2. Pain relief after SRS. Tumor targeting: BNI I (a) and BNI I-IIIb (b). c Tumor and nerve targeting: BNI I-IIIb.

rate was much higher, at $26.7 \%$, in the only series that reported them after targeting both the nerve and the tumor. The most common complication was facial numbness.

TN secondary to benign skull-base tumors is a specific case scenario. Of interest are both tumor control and symptomatic improvement. Microsurgical resection has the advantage of a decrease in both the tumor volume and the mass effect on the nerve. In tumor-related cases, Barker et al. [6] reported a series with a mean postoperative follow-up of 9 years, with frequent and long-lasting pain relief, i.e., complete, as high as $81 \%$ at 10 years after surgery, and partial, $4 \%$. In the surgical series, new cranial nerve neuropathies were reported in $6.25-19.2 \%$ of cases $[6,8,10]$. In selected cases, SRS, and gamma knife surgery in particular, has been shown to be safe and effective in the long term in large cohorts of skull-base meningiomas [28-31] and VS [32-34].

With regard to the clinical aspects, several issues warrant further discussion. Bullitt et al. [7] suggested that the specific trigeminal site of the tumor influences symptoms and signs, i.e., tumors that are peripherally placed cause atypical TN, those in the middle fossa cause severe atypical TN, and those in the posterior fossa cause typical TN. The mechanism that generates pain is considered to be direct trigeminal root compression or vascu-
12

Stereotact Funct Neurosurg 2021;99:6-16 DOI: $10.1159 / 000509842$
Peciu-Florianu et al. 
a Pain-free at last follow-up (BNI I)

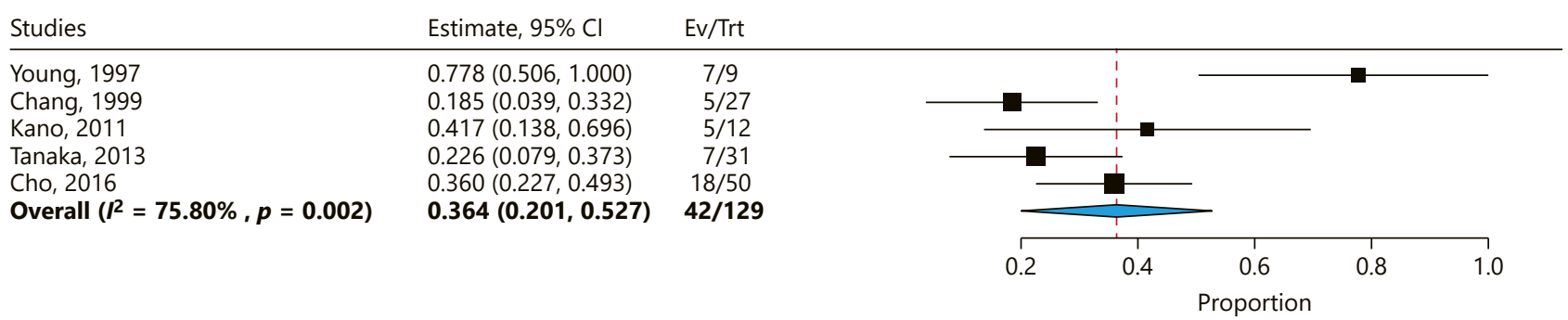

b Pain-free at last follow-up (BNI I-IIlb)

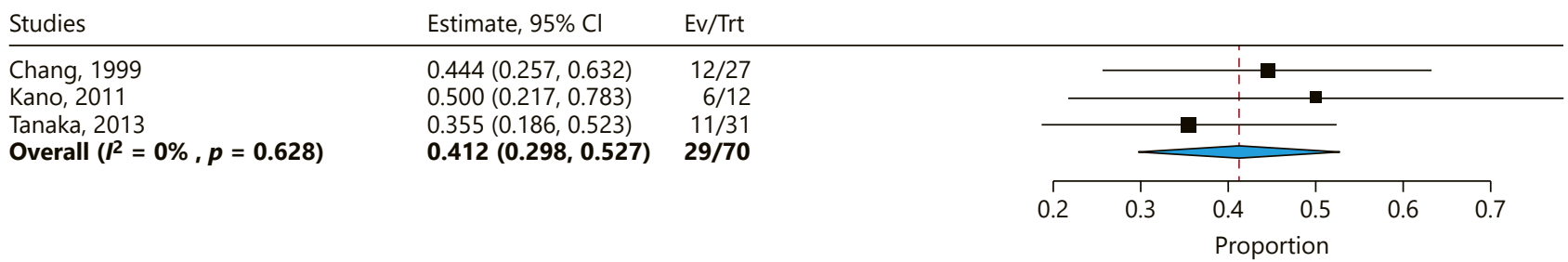

Fig. 3. Pain-free at last follow-up (tumor targeting), BNI I (a) and BNI I-IIIb (b).

lar compression secondary to a displacement by the tumor [6].

While the tumor is the primary target, the mechanism of action of SRS in secondary TN remains largely undiscovered. However, Régis et al. [35] suggested that there are different mechanisms of action for the relief of secondary tumor-related facial pain by SRS, and they performed experimental studies to confirm this. Chang et al. [11] suggested that reduced abnormal electrical transmission might explain such changes. Huang et al. [14] suggested that the volume of demyelination of the nerves in tumors is probably higher than in idiopathic $\mathrm{TN}$, as is the volume of radiation during treatment. Thus, the dose threshold for pain relief may be lower in the tumor condition. In fact, the maximum dose prescribed for idiopathic TN (70-90 Gy) is much higher $[4,5]$ than that prescribed for tumors (26-32 Gy) [28, 29]. Some authors include neuropathic pain cases, and report that patients are not responsive to SRS [17].

An open question is whether tumor response, particularly tumor decrease, after SRS is linked with alleviating TN. Chang et al. [11] reported 1 case in which pain disappeared and 3 cases with pain reduction in a series of 27 cases, even though there were no changes in tumor volume during follow-up. Huang et al. [14] suggested that tumor shrinkage may help with the relief of tic doulou-

SRS for Trigeminal Neuralgia Secondary to Tumors reux. In sum, tumor shrinkage was associated with pain relief in some of the series [14], while other authors did not find any associations [15]. Some series suggested that pain recurs more often in patients with meningiomas than in those with VS [13].

Overall, complications were rare. The most common complication was facial numbness. Beside numbness, Chang et al. [11] reported transient tinnitus and diminished hearing (in the VS context). Interestingly, there were no cases reported of corneal anesthesia or anesthesia dolorosa. Other complications included balance problems [18], masseter weakness [19], abducens palsy [19], and ipsilateral hemispheric stroke [19]. Kim et al. [21] reported a series of single-session SRS targeting of both nerve and tumor, with no further facial weakness, altered taste function, or hearing and balance difficulties. Of note, hearing loss seems to be encountered more with VS than with meningiomas of the skull-base, as reported in recent studies [36, 37].

In the near future, treatment should be tailored to a patient's specific needs, as suggested by other groups using SRS (Cyberknife, Accuray) which have reported their algorithm in dealing with tumor-related facial pain, e.g., the Stanford group, using a dose regimen of 18-21 Gy in 3 fractions [38]. Specific issues remain to be developed by further studies: local control might not necessarily im- 
a Recurrence

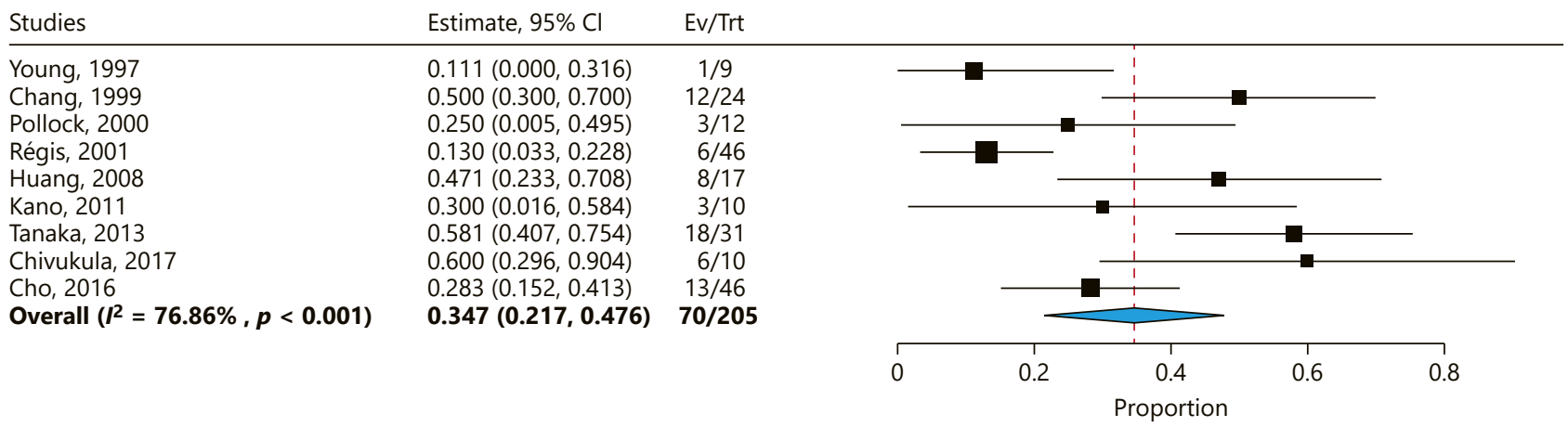

\section{b Complications}

\begin{tabular}{llc} 
Studies & Estimate, 95\% Cl & Ev/Trt \\
\hline Chang, 1999 & $0.222(0.065,0.379)$ & $6 / 27$ \\
Régis, 2001 & $0.043(0.000,0.102)$ & $2 / 46$ \\
Kreil, 2005 & $0.125(0.000,0.287)$ & $2 / 16$ \\
Huang, 2008 & $0.190(0.023,0.358)$ & $4 / 21$ \\
Squire, 2012 & $0.095(0.000,0.221)$ & $2 / 21$ \\
Tanaka, 2013 & $0.161(0.032,0.291)$ & $5 / 31$ \\
Chivukula, 2017 & $0.250(0.005,0.495)$ & $3 / 12$ \\
Overall $(\boldsymbol{I}=\mathbf{3 5 . 9 5 \% , p = 0 . 1 5 4 )}$ & $\mathbf{0 . 1 2 6}(\mathbf{0 . 0 6 3}, \mathbf{0 . 1 8 8})$ & $\mathbf{2 4 / 1 7 4}$
\end{tabular}

Fig. 4. a Recurrence. b Complications.

prove symptomatology, pain relief might occur after a latency period, and benign tumors respond slow to irradiation.

The most difficult question to answer, from currently available data, is: What is the appropriate target? Moreover, should this be followed by a second targeting, in the same session, or a long time after the first? Would a boost to the nerve be necessary if the tumor is the target?

This analysis had some limitations. The first is the retrospective nature of the included series. The second is related to the fact that some reports included other pathologies besides meningiomas and VS, although in a minor proportion; this might have influenced some of the outcomes. The third is that not all the authors used the BNI or other standard scales for reporting. The fourth is that several studies included malignant or biologically aggressive cases. The fifth, which applies to all TN studies, was the examination of the final outcome, which should be based on clinical examinations rather than telephone interviews. The sixth is that preoperative analysis re- vealed neuropathic pain in some of the cases. The seventh is related to the imbalance in the number of patients undergoing the different targeting techniques, with a particularly a low number of cases in which both the nerve and tumor were targeted.

\section{Conclusions}

SRS for benign tumors, such as meningiomas and VS, is associated with favorable clinical outcomes, although not as much as SRS for idiopathic TN. The current literature illustrates heterogeneity in targeting policy and reporting of the results.

Though targeting both the nerve and the tumor seems to achieve better long-term results, the rate of complications is much higher and the number of patients treated is limited. Future reports should focus on potential randomization between different targeting techniques and uniformity in reporting the results.
Peciu-Florianu et al. 


\section{Acknowledgment}

The authors thank Lausanne University Hospital and the Faculty of Biology and Medicine, University of Lausanne.

\section{Statement of Ethics}

The research presented here was conducted in accordance with the World Medical Association Declaration of Helsinki, the appropriate guidelines for human studies, and animal welfare regulations including the Animal Research: Reporting of in vivo Experiments (ARRIVE) guidelines. It was approved by the appropriate institutional review bodies. For this type of study, formal ethics committee approval is not necessary.

\section{Conflict of Interest Statement}

C.T. is a scientific advisor for Elekta Instruments, AB, Sweden, but with no relation to this paper. The other authors report no conflicts of interest.

\section{Funding Sources}

C.T. gratefully acknowledges receipt of a "Young Researcher in Clinical Research Grant" ("Jeune Chercheur en Recherche Clinique") from the Faculty of Biology and Medicine, University of Lausanne, and the Lausanne University Hospital (CHUV).

\section{Author Contributions}

Each author (1) made substantial contributions to the conception or design of the work, or to the acquisition, analysis, or interpretation of data for the work; (2) participated in drafting the work or revising it critically for important intellectual content; (3) approved the final version to be published; and (4) agreed to be accountable for all aspects of the work in ensuring that questions related to the accuracy or integrity of any part of the work are appropriately investigated and resolved.

\section{References}

1 Barker FG 2nd, Jannetta PJ, Bissonette DJ, Larkins MV, Jho HD. The long-term outcome of microvascular decompression for trigeminal neuralgia. N Engl J Med. 1996 Apr; 334(17):1077-83.

2 Tuleasca C, Carron R, Resseguier N, Donnet A, Roussel P, Gaudart J, et al. Decreased Probability of Initial Pain Cessation in Classic Trigeminal Neuralgia Treated With Gamma Knife Surgery in Case of Previous Microvascular Decompression: A Prospective Series of 45 Patients With $>1$ Year of Follow-up. Neurosurgery. $2015 \mathrm{Jul} ; 77(1): 87-94$.

3 Lopez BC, Hamlyn PJ, Zakrzewska JM. Systematic review of ablative neurosurgical techniques for the treatment of trigeminal neuralgia. Neurosurgery. 2004 Apr;54(4):973-82.

4 Kondziolka D, Zorro O, Lobato-Polo J, Kano $\mathrm{H}$, Flannery TJ, Flickinger JC, et al. Gamma Knife stereotactic radiosurgery for idiopathic trigeminal neuralgia. J Neurosurg. 2010 Apr; 112(4):758-65.

5 Tuleasca C, Régis J, Sahgal A, De Salles A, Hayashi M, Ma L, et al. Stereotactic radiosurgery for trigeminal neuralgia: a systematic review. J Neurosurg. 2018 Apr;130(3): 733-57.

6 Barker FG 2nd, Jannetta PJ, Babu RP, Pomonis S, Bissonette DJ, Jho HD. Long-term outcome after operation for trigeminal neuralgia in patients with posterior fossa tumors. J Neurosurg. 1996 May;84(5):818-25.

7 Bullitt E, Tew JM, Boyd J. Intracranial tumors in patients with facial pain. J Neurosurg. 1986 Jun;64(6):865-71.
8 Cheng TM, Cascino TL, Onofrio BM. Comprehensive study of diagnosis and treatment of trigeminal neuralgia secondary to tumors. Neurology. 1993 Nov;43(11):2298-302.

9 Pollock BE, Iuliano BA, Foote RL, Gorman DA. Stereotactic radiosurgery for tumor-related trigeminal pain. Neurosurgery. 2000 Mar;46(3):576-82.

10 Delfini R, Innocenzi G, Ciappetta P, Domenicucci M, Cantore G. Meningiomas of Meckel's cave. Neurosurgery. 1992 Dec;31(6): 1000-6.

11 Chang JW, Kim SH, Huh R, Park YG, Chung SS. The effects of stereotactic radiosurgery on secondary facial pain. Stereotact Funct Neurosurg. 1999;72 Suppl 1:29-37.

12 Chivukula S, Kim W, Zhuo X, Tenn S, Kaprealian T, DeSalles A, et al. Radiosurgery for Secondary Trigeminal Neuralgia: Revisiting the Treatment Paradigm. World Neurosurg. 2017 Mar;99:288-94.

13 Cho KR, Lee MH, Im YS, Kong DS, Seol HJ, Nam DH, et al. Gamma knife radiosurgery for trigeminal neuralgia secondary to benign lesions. Headache. 2016 May;56(5):883-9.

14 Huang CF, Tu HT, Liu WS, Lin LY. Gamma Knife surgery for trigeminal pain caused by benign brain tumors. J Neurosurg. 2008 Dec; 109 Suppl:154-9.

15 Kano H, Awan NR, Flannery TJ, Iyer A, Flickinger JC, Lunsford LD, et al. Stereotactic radiosurgery for patients with trigeminal neuralgia associated with petroclival meningiomas. Stereotact Funct Neurosurg. 2011; 89(1):17-24.
16 Kreil W, Luggin J, Fuchs I, Weigl V, Eustacchio S, Papaefthymiou G. Long term experience of gamma knife radiosurgery for benign skull base meningiomas. J Neurol Neurosurg Psychiatry. 2005 Oct;76(10):1425-30.

17 Régis J, Metellus P, Dufour H, Roche PH, Muracciole X, Pellet $\mathrm{W}$, et al. Long-term outcome after gamma knife surgery for secondary trigeminal neuralgia. J Neurosurg. 2001 Aug; 95(2):199-205.

18 Squire SE, Chan MD, Furr RM, Lowell DA, Tatter SB, Ellis TL, et al. Gamma knife radiosurgery in the treatment of tumor-related facial pain. Stereotact Funct Neurosurg. 2012; 90(3):145-50.

19 Tanaka S, Pollock BE, Stafford SL, Link MJ. Stereotactic radiosurgery for trigeminal pain secondary to benign skull base tumors. World Neurosurg. 2013 Sep-Oct;80(3-4):371-7.

20 Young RF, Vermeulen SS, Grimm P, Blasko J, Posewitz A. Gamma Knife radiosurgery for treatment of trigeminal neuralgia: idiopathic and tumor related. Neurology. 1997 Mar; 48(3):608-14.

21 Kim SK, Kim DG, Se YB, Kim JW, Kim YH, Chung HT, et al. Gamma Knife surgery for tumor-related trigeminal neuralgia: targeting both the tumor and the trigeminal root exit zone in a single session. J Neurosurg. 2016 Oct;125(4):838-44.

22 Park SC, Lee DH, Lee JK. Two-Session Tumor and Retrogasserian Trigeminal Nerve-Targeted Gamma Knife Radiosurgery for Secondary Trigeminal Neuralgia Associated with Benign Tumors. World Neurosurg. 2016 Dec; 96:136-47. 
23 Kano H, Niranjan A, Kondziolka D, Flickinger JC, Dade Lunsford L. Stereotactic radiosurgery for trigeminal schwannoma: tumor control and functional preservation Clinical article. J Neurosurg. 2009 Mar;110(3):553-8.

24 Phan J, Pollard C, Brown PD, Guha-Thakurta N, Garden AS, Rosenthal DI, et al. Stereotactic radiosurgery for trigeminal pain secondary to recurrent malignant skull base tumors. J Neurosurg. 2018 Apr;130(3):812-21.

25 Moher D, Liberati A, Tetzlaff J, Altman DG; PRISMA Group. Reprint-preferred reporting items for systematic reviews and metaanalyses: the PRISMA statement. Phys Ther. 2009 Sep;89(9):873-80.

26 Rogers CL, Shetter AG, Fiedler JA, Smith KA, Han PP, Speiser BL. Gamma knife radiosurgery for trigeminal neuralgia: the initial experience of The Barrow Neurological Institute. Int J Radiat Oncol Biol Phys. 2000 Jul;47(4) 1013-9.

27 Flickinger JC, Kondziolka D, Maitz AH Lunsford LD. Gamma knife radiosurgery of imaging-diagnosed intracranial meningioma. Int J Radiat Oncol Biol Phys. 2003 Jul;56(3): 801-6.

28 Cohen-Inbar O, Lee CC, Schlesinger D, Xu Z, Sheehan JP. Long-Term Results of Stereotactic Radiosurgery for Skull Base Meningiomas. Neurosurgery. 2016 Jul;79(1):58-68.
29 Cohen-Inbar O, Tata A, Moosa S, Lee CC, Sheehan JP. Stereotactic radiosurgery in the treatment of parasellar meningiomas: longterm volumetric evaluation. J Neurosurg. 2018 Feb;128(2):362-72.

30 Iwai Y, Yamanaka K, Shimohonji W, Ishibashi K. Staged Gamma Knife Radiosurgery for Large Skull Base Meningiomas. Cureus. 2019 Oct;11(10):e6001.

31 Starke RM, Przybylowski CJ, Sugoto M, Fezeu F, Awad AJ, Ding D, et al. Gamma Knife radiosurgery of large skull base meningiomas. J Neurosurg. 2015 Feb;122(2):363-72.

32 Kondziolka D, Mousavi SH, Kano H, Flickinger JC, Lunsford LD. The newly diagnosed vestibular schwannoma: radiosurgery, resection, or observation? Neurosurg Focus. 2012 Sep;33(3):E8.

33 Tsao MN, Sahgal A, Xu W, De Salles A, Hayashi M, Levivier M, et al. Stereotactic radiosurgery for vestibular schwannoma: International Stereotactic Radiosurgery Society (ISRS) Practice Guideline. J Radiosurg SBRT. 2017;5(1):5-24.
34 Tuleasca C, George M, Faouzi M, Schiappacasse L, Leroy HA, Zeverino M, et al. Acute clinical adverse radiation effects after Gamma Knife surgery for vestibular schwannomas. J Neurosurg. 2016 Dec;125 Suppl 1:73-82.

35 Régis J, Métellus P, Lazorthes Y, Porcheron D, Peragut JC. Effect of gamma knife on secondary trigeminal neuralgia. Stereotact Funct Neurosurg. 1998 Oct;70 Suppl 1:210-7.

36 Carlstrom LP, Jacob JT, Graffeo CS, Perry A, Oldenburg MS, Foote RL, et al. Impact of cochlear modiolus dose on hearing preservation following stereotactic radiosurgery for nonvestibular schwannoma neoplasms of the lateral skull base: a cohort study. J Neurosurg. 2019, Online ahead of print.

37 El-Shehaby AM, Reda WA, Abdel Karim KM, Nabeel AM, Emad Eldin RM, Tawadros SR. Hearing preservation after Gamma Knife radiosurgery for cerebellopontine angle meningiomas. J Neurosurg. 2018 Dec;129 Suppl 1: 38-46.

38 Murovic JA, Chang SD. A critical analysis of the literature review in "Stereotactic radiosurgery for trigeminal pain secondary to benign skull base tumors" by Tanaka et al. and presentation of an algorithm for management of these tumors. World Neurosurg. 2013 SepOct;80(3-4):287-9. 